\title{
Heat-stimulated transformation of zirconium dioxide nanocrystals produced under hydrothermal conditions
}

\author{
O. V. Almjasheva \\ Saint Petersburg Electrotechnical University "LETI", St. Petersburg, Russia \\ almjasheva@mail.ru
}

PACS 61.46. $+\mathrm{w}$

DOI 10.17586/2220-8054-2015-6-5-697-703

Processes occurring during the thermal treatment of nanocrystalline zirconium dioxide are reviewed. Changes in the dimensions and structure of $\mathrm{ZrO}_{2}$ that occur depend upon the calcination conditions used.

Keywords: zirconium dioxide, $\mathrm{ZrO}_{2}$, hydrothermal synthesis, phase formation, formation mechanism.

Received: 1 October 2015

\section{Introduction}

Many publications (see, e.g., [1- 12]) have studied the formation of various structural forms of $\mathrm{ZrO}_{2}$ nanocrystals and have analyzed the reasons for the relatively high stability of the thermodynamically non-equilibrium modifications in nanocrystalline zirconium dioxide at relatively low temperatures. Publications [1-3] link this peculiarity of zirconium dioxide nanocrystals to a dimensional effect. Publications [4-12] examined the impact of the methods and parameters of $\mathrm{ZrO}_{2}$ nanocrystal synthesis on their structure, morphology and properties. Studies on the mechanism for nanocrystalline zirconium dioxide formation $[4,5,14,15]$ and its behavior during heating $[3,7,16]$ indicated that a more detailed analysis was needed of the impact of the reaction system prehistory on the process of $\mathrm{ZrO}_{2}$ nanoparticle crystallisation.

The study of zirconium dioxide nanocrystals by comprehensive thermal analysis [1619] has revealed a number of unusual effects in their behavior. Numerous publications [16-19] that have used this method to study the processes occurring in $\mathrm{ZrO}_{2}$ particles obtained by different methods have reported an intensive exothermic effect in the $200-500^{\circ} \mathrm{C}$ temperature range which was accompanied by a loss of mass. The appearance of an exothermic effect in the $400-500^{\circ} \mathrm{C}$ temperature range is explained in publications [15-18] by the crystallisation of X-ray amorphous $\mathrm{ZrO}_{2}$. The authors of publications [19, 20] attribute the exothermic effect to oxidation of carbon-containing compounds because nanocrystalline $\mathrm{ZrO}_{2}$ was produced using zirconium oxalate, butanediol or other organic reagents. Publications [4, 5, $7,8,16,21-27$ explain the stabilization of the tetragonal (pseudo-cubic) modification of zirconium dioxide in the low-temperature range by the inclusion of water into the nanoparticle structure, while removal of water during heating initiates a structural rearrangement, accompanied by an exothermic effect.

The lack of a clear interpretation of the reasons for structural changes in the zirconium dioxide-based nanocrystals, including those accompanied by an exothermic effect with a simultaneous loss in mass during heating, requires a detailed study of these transformations.

\section{Experimental methods}

Zirconium dioxide nanocrystals were produced by hydrothermal processing of zirconium oxyhydroxide precipitated from a $\mathrm{ZrOCl}_{2}$ solution by the technique described in [28]. 
The "isothermic calcination-quenching" method, using a specially designed furnace to ensure high sample heating and cooling rates, studied the structural change kinetics in the condition and dimensions of the zirconium dioxide nanocrystals depending on temperature and heat treatment duration.

The X-ray diffraction study was made on a DRON-3M diffractometer, $\mathrm{CuK}_{\alpha}$-radiation. Quantitative analysis of the tetragonal $\left(t-\mathrm{ZrO}_{2}\right)$ and monoclinic $\left(m-\mathrm{ZrO}_{2}\right)$ forms of zirconium dioxide and precise determination of the position of the diffraction maximums were conducted using the method of an internal reference introduction $\left(\alpha-\mathrm{Al}_{2} \mathrm{O}_{3}\right)$. The size and shape of the crystallites were determined in accordance with the recommendations of publication [9] based on the data on expansion of the X-ray diffraction line and high-resolution transmission electron microscopy (Jeol JEM-200).

\section{Results and discussion}

Based on X-ray phase analysis (Fig. 1), the nanoparticles produced under hydrothermal conditions consisted of two structural modifications: $t-\mathrm{ZrO}_{2}$ and $m-\mathrm{ZrO}_{2}$. Quantitative calculation of the $t-\mathrm{ZrO}_{2}$ and $m-\mathrm{ZrO}_{2}$ content, performed by the technique described in publication [28], showed that $80 \pm 5 \% t-\mathrm{ZrO}_{2}$ and $20 \pm 5 \% m-\mathrm{ZrO}_{2}$ are present in the system.

It should be noted that this ratio of $t-\mathrm{ZrO}_{2} / m-\mathrm{ZrO}_{2}$ is fairly stable and typical for the technique used to obtain the nanoparticles, as confirmed by the results of previous studies $[4,5,7,14-16,25,27,28]$.

The dimensions of $\mathrm{ZrO}_{2}$ nanocrystals, which were determined by both transmission electron microscopy (Fig. 2) and based on data from the expansion of the X-ray diffraction lines (Fig. 1) for $t-\mathrm{ZrO}_{2}$ and $m-\mathrm{ZrO}_{2}$, essentially coincided and were $20 \pm 3 \mathrm{~nm}$, on the basis of which it can be concluded that the nanoparticles produced under hydrothermal conditions were monocrystalline. Structural analysis results for individual nanoparticles by high-resolution transmission electron microscopy also attest to the monocrystalline nature of the produced zirconium dioxide nanoparticles and the fusion on the edges of individual nanocrystals. It is noted that the resulting $\mathrm{ZrO}_{2}$ nanocrystal dimensions are reproduced fairly consistently when $\mathrm{ZrO}_{2}$ nanocrystals are synthesised under hydrothermal conditions, as follows from the results of previous studies (see, e.g., [5, 9, 14, 28]). The dimensions of the $\mathrm{ZrO}_{2}$ nanocrystals may be reduced somewhat to $15-18 \mathrm{~nm}$ by reducing the duration of hydrothermal treatment [5], however in this case, zirconium oxyhydroxide is generally not completely dehydrated [5]. We therefore used such hydrothermal processing conditions for zirconium oxyhydroxide which result in its complete dehydration with the formation of $\mathrm{ZrO}_{2}$ nanocrystals, according to the data of publication [5].

The results from the kinetic study of the change in zirconium dioxide nanocrystal structure and size when heated in the "isothermic calcination-quenching" mode are shown in Fig. 2. Three temperature regions with varying nanoparticle behavior are isolated, based on analysis of the resulting dependences of the quantity of tetragonal modification and particle size of zirconium dioxide on the temperature and duration of treatment (Fig. 2). This temperature ranges to $500^{\circ} \mathrm{C}$, from 600 to $800^{\circ} \mathrm{C}$ and from 900 to $1100^{\circ} \mathrm{C}$.

After thermal treatment of the nanoparticles at temperatures up to $500^{\circ} \mathrm{C}$, there are no noticeable changes in the structure or particle size of $\mathrm{ZrO}_{2}$ (Fig. 2). It is also precisely in this temperature range that significant exothermic effects are observed, accompanied by simultaneous water release [16]. Since the total quantity of crystalline $\mathrm{ZrO}_{2}$, the ratio of metastable tetragonal and monoclinic zirconium dioxide modifications, and the sizes of the nanocrystals during thermal treatment in the examined temperature range do not essentially 
- $m-\mathrm{ZrO}_{2}$

$-t-\mathrm{ZrO}_{2}$

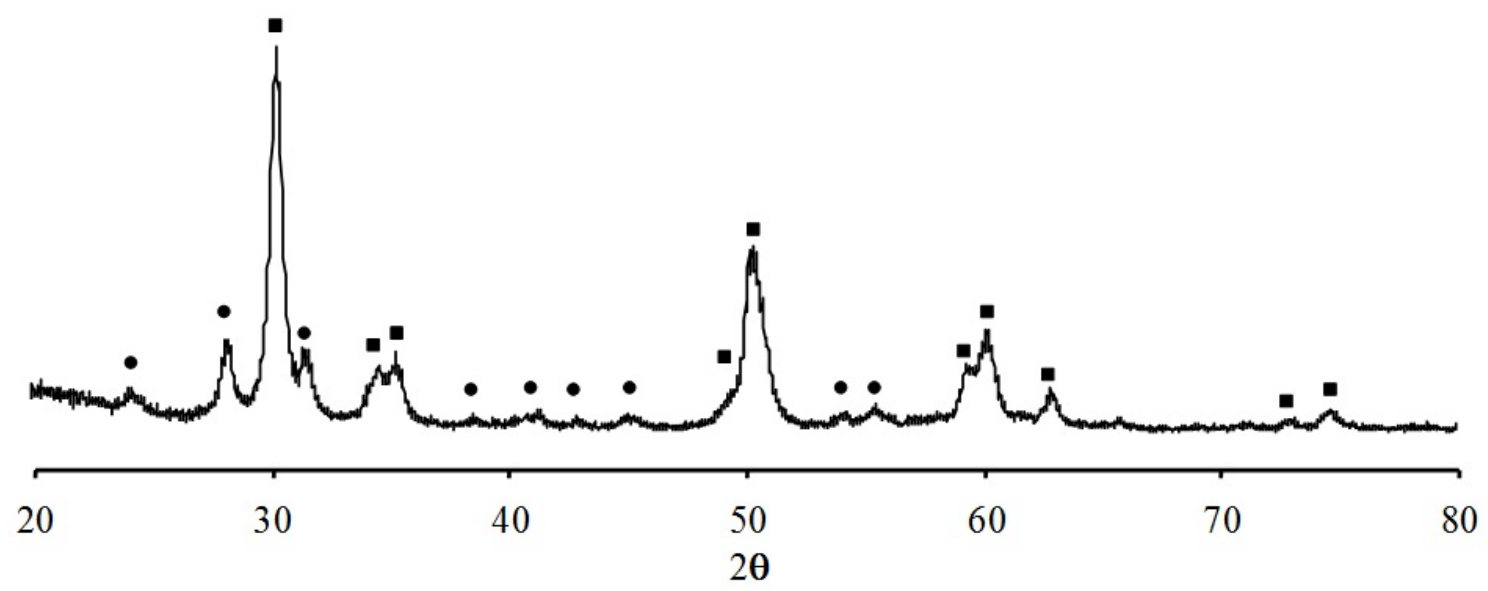

FIG. 1. X-ray diffraction of the nanocrystalline zirconium dioxide, obtained by hydrothermal synthesis
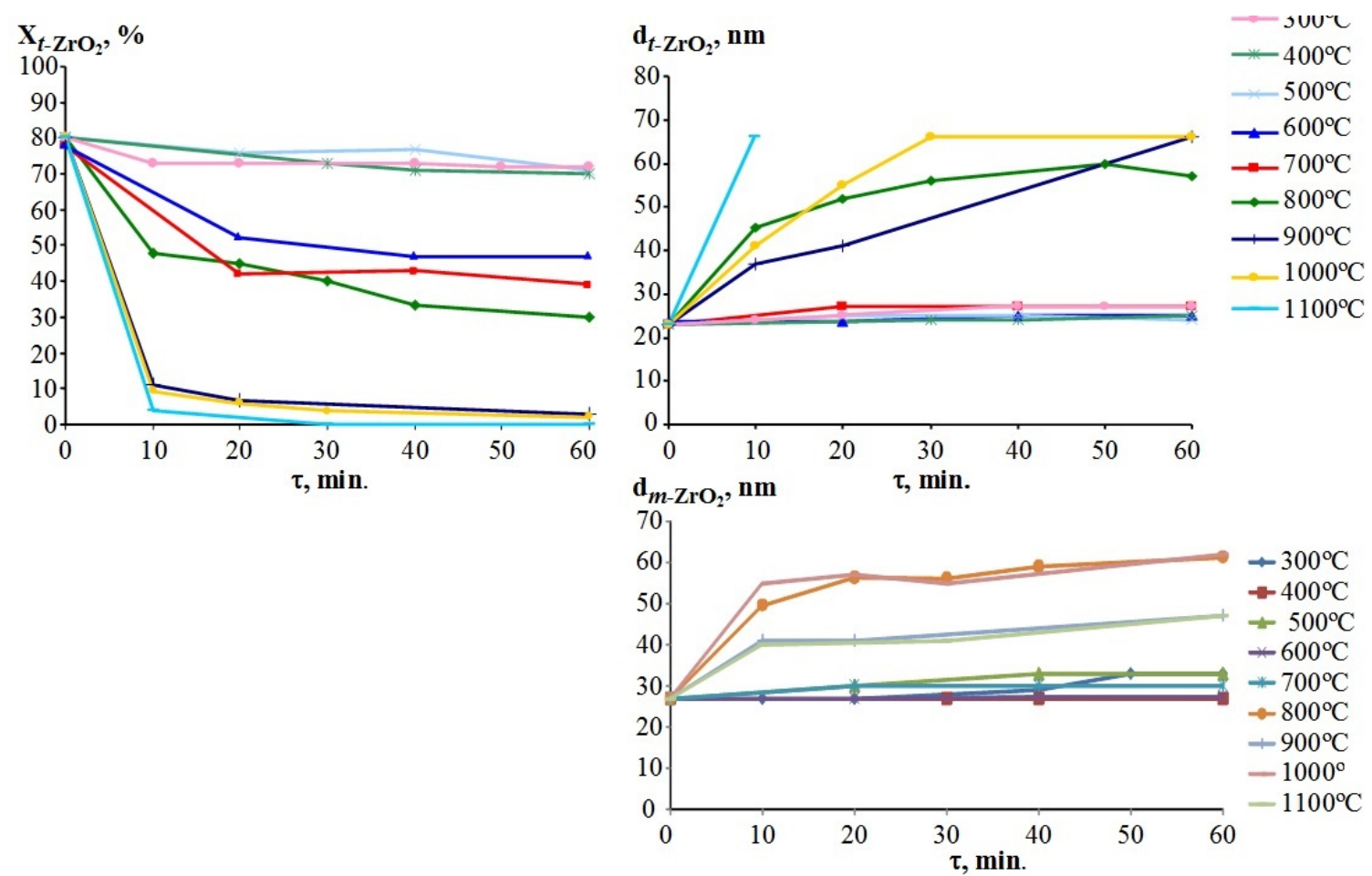

a

b

FIG. 2. The dependence of the amount of $t-\mathrm{ZrO}_{2}$ (a) and crystallite size $t-\mathrm{ZrO}_{2}$ and $m-\mathrm{ZrO}_{2}(\mathrm{~b})$ of the duration and temperature of heat treatment 
change (Fig. 2), there are no grounds to classify the observed thermal effects as crystallization of amorphous zirconium dioxide, polymorphous transition $t-\mathrm{ZrO}_{2} \rightarrow m-\mathrm{ZrO}_{2}$ or change in surface energy because of growth in nanoparticle grains. The process leading to heat release could be structural rearrangement in the nanocrystals, which does not cause transformation of one polymorphous modification of zirconium dioxide nanoparticles into another, and linked, for example, to relaxation processes in nanoparticle sublattices, primarily and apparently in the anion sublattice. The structural changes in the anion sublattice may be initiated, in particular, by certain dehydration reactions in the nanocrystals:

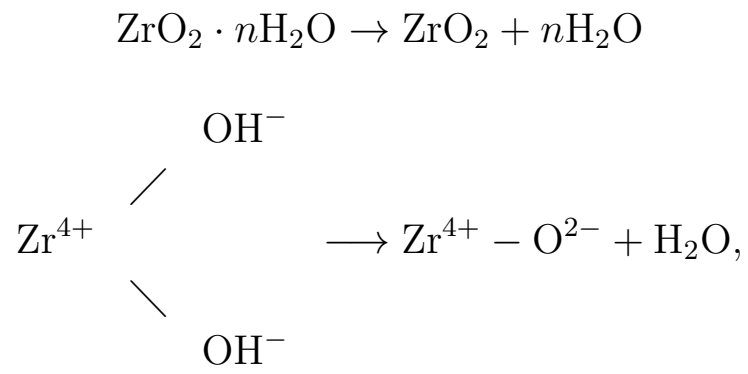

which alter the anion sublattice structure, and consequently, create conditions for the occurrence of relaxation processes, which reduce the system internal energy, i.e., occurring with an exothermic effect. The presence of structural changes in the nanocrystals, accompanying the dehydration process is confirmed by data indicating a change in the position and ratio of the intensity of X-ray diffraction lines in $t-\mathrm{ZrO}_{2}$.

\begin{tabular}{|c|c|c|c|c|}
\hline $\mathrm{t}-\mathrm{ZrO}_{2}$ & h k l & $\mathrm{d} / \mathbf{n}$ & h k l & $\mathrm{d} / \mathbf{n}$ \\
\hline Standard (24-1164) & \multirow{3}{*}{101} & 2.995 & \multirow{3}{*}{002} & 2.635 \\
\hline Original sample & & 2.971 & & 2.601 \\
\hline Sample after heat treatment at $500^{\circ} \mathrm{C}$ & & 2.951 & & 2.592 \\
\hline
\end{tabular}

The proposed interpretation of $t-\mathrm{ZrO}_{2}$ nanocrystal behavior in the $500^{\circ} \mathrm{C}$ temperature range correlates with previous zirconium dioxide structural study results indicating that its structure in the planes $\left(\begin{array}{lll}1 & 0 & 1\end{array}\right)$ coincides with the $t-\mathrm{ZrO}_{2}$ structure [29]. The difference in the structure between zirconium X-ray amorphous hydroxide and tetragonal dioxide, according to publication [28-30] is that in the first case, the planes $\left(\begin{array}{lll}1 & 0 & 1\end{array}\right)$ are arranged randomly. Since, according to data $[10,11,26]$, during zirconium hydroxide dehydration under hydrothermal conditions, the formed $\mathrm{ZrO}_{2}$ nanoparticles inherit the structure of the hydrate precursor, one can thus hypothesize that the formed $t-\mathrm{ZrO}_{2}$ nanoparticles also inherit the random arrangement of anions between the planes $\left(\begin{array}{lll}1 & 0 & 1\end{array}\right)$. This random atom arrangement in the anion sublattice will thus be stabilized by the presence of water in it $[2,7,14,16]$, while the dehydration processes (1) and/or (2) initiate a more orderly arrangement of $\mathrm{O}^{2-}$ ions, which, apparently, also causes the corresponding exothermic effects [16].

Heat treatment in the $600-700^{\circ} \mathrm{C}$ temperature range results in a noticeable increase in the amount of $\mathrm{ZrO}_{2}$ monoclinic modification (up to 50\%), while the particle size does not essentially change. Mass loss by the sample due to water release during $t-\mathrm{ZrO}_{2} \rightarrow m-\mathrm{ZrO}_{2}$ transformation, which is slight in this temperature range, is only about 0.5 mass\% [16]. At the same time, as shown by the nanoparticle study using high-resolution transmission electron microscopy, after heat treatment of nanoparticles in this temperature range, their morphology changes significantly (Fig. 3). They are converted from essentially non-faced particles into well-faced particles with the characteristic shape for crystallites of the relevant 
structural modifications (Fig. 3). This is apparently caused by activation of atom movement in the nanoparticles in this temperature range. We also note that an increase in the percentage of $m-\mathrm{ZrO}_{2}$ nanoparticles to $50 \%$ without a change in their mean size was observed previously [29] for the behavior of zirconium dioxide nanoparticles by thermal radiography when heated to $800^{\circ} \mathrm{C}$.

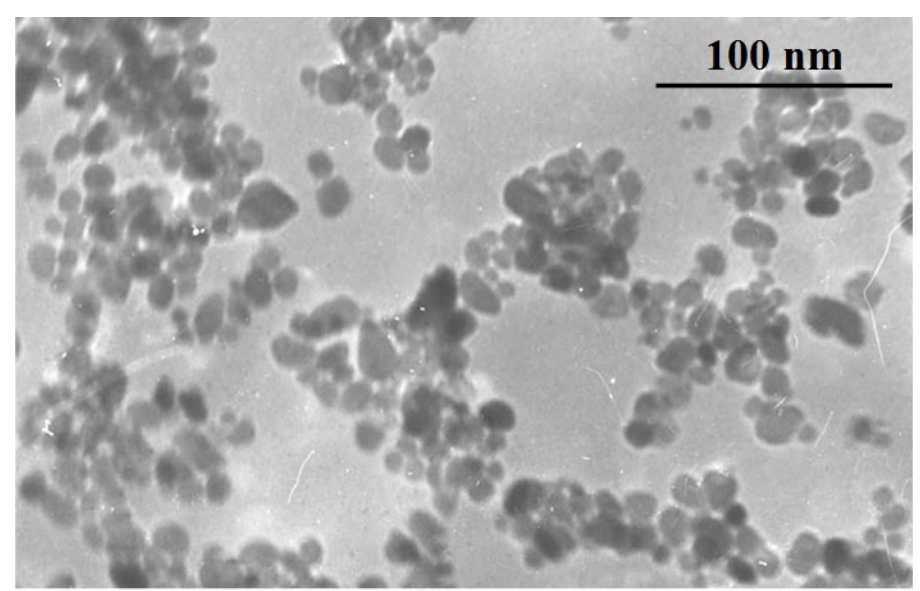

a

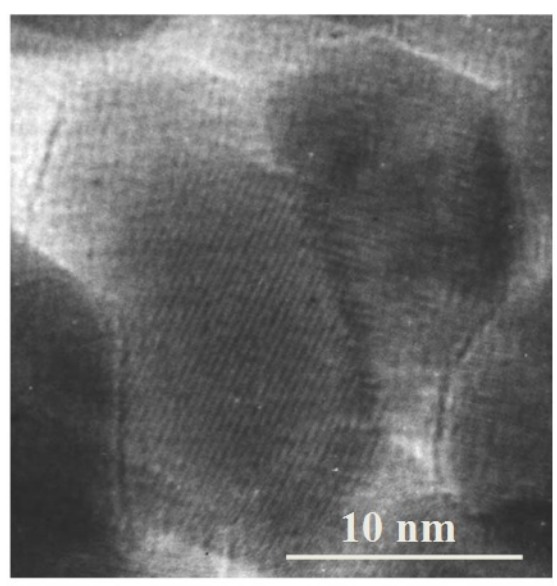

b

FIG. 3. Microphotographs of $\mathrm{ZrO}_{2}$ nanocrystals, obtained in hydrothermal conditions (a) and after heat treatment at $700^{\circ} \mathrm{C}$

It follows from the kinetic studies (Fig. 2) that for the $900-1100^{\circ} \mathrm{C}$ temperature range, structural transformation $t-\mathrm{ZrO}_{2} \rightarrow m-\mathrm{ZrO}_{2}$ ends completely, while the size of the $m-\mathrm{ZrO}_{2}$ nanocrystals more than doubles to 50-60 nm (Fig. 2). Based on thermal analysis, in addition to the exothermic conversion, a slight water release is observed here, leading to mass loss by the sample of about 0.1 mass \% [16]. It is noted that in the $900-1000^{\circ} \mathrm{C}$ temperature range, in addition to the growth of $m-\mathrm{ZrO}_{2}$ nanocrystals, there is a growth of $t-\mathrm{ZrO}_{2}$ nanocrystals (Fig. 2). This type of change in the nanoparticle dimensions is apparently due to activation of mass transfer at these temperatures both between the nanoparticles of one structural modification and transfer of matter from the non-equilibrium structural modification of $t$ $\mathrm{ZrO}_{2}$ at this temperature to equilibrium $m-\mathrm{ZrO}_{2}$.

The findings, as well as the fact that $t-\mathrm{ZrO}_{2} \rightarrow m-\mathrm{ZrO}_{2}$ transformation may occur essentially without a change in particle size supports the weak impact of the dimensional effect on nanoparticle $t-\mathrm{ZrO}_{2}$ stability at low temperatures, as indicated in a number of publications $[1,2]$. The stabilizing effect of the water, localized in the anion sublattice of the zirconium dioxide nanoparticle is the primary factor which determines the stability of $t-\mathrm{ZrO}_{2}$ nanoparticles at temperatures up to $500^{\circ} \mathrm{C}$.

\section{Conclusion}

It has been shown that the occurring changes in $\mathrm{ZrO}_{2}$ nanoparticles in the $300-500^{\circ} \mathrm{C}$ temperature range are linked to the release of water, accompanied by an exothermic effect, to all appearances determined by structural re-arrangement in the $t-\mathrm{ZrO}_{2}$ nanocrystals, initiated by dehydration, and resulting in a more orderly arrangement of the atoms in the anion sublattice.

The $t-\mathrm{ZrO}_{2} \rightarrow m-\mathrm{ZrO}_{2}$ transition in the 600 to $800^{\circ} \mathrm{C}$ temperature range essentially occurs without a change in nanocrystallite size, but with a noticeable water loss. Removal of the stabilizing water from the $t-\mathrm{ZrO}_{2}$ structure also results in a transition of the metastable 
tetragonal modification of zirconium dioxide to that of the monoclinic $\mathrm{ZrO}_{2}$ modification which is stable at these temperatures.

In the 800 to $1100^{\circ} \mathrm{C}$ temperature range, mass transfer from the non-equilibrium $t$ $\mathrm{ZrO}_{2}$ nanocrystallites to the $m-\mathrm{ZrO}_{2}$ equilibrium phase makes a significant contribution to the increase in the percentage of $m-\mathrm{ZrO}_{2}$ nanocrystals.

\section{Acknowledgments}

The author would like to thank Prof. V. V. Gusarov for interest in the work and help in the interpretation of results.

This work was supported by the Russian Foundation for Basic Research (project 1308-01207).

\section{References}

[1] Garvie R.C. The Occurrence of Metastable tetragonal zirconia as a crystallite size effect. The Journal of Physical chemistry, 1965, 69(4), P. 1238.

[2] Shukla S., Seal S. Mechanism of room temperature metastable tetragonal phase stabilisation in zirconia. International materials reviews, 2005, 50(1), P. 45.

[3] Bugrov A.N., Almjasheva O.V., Effect of hydrothermal synthesis conditions on the morphology of $\mathrm{ZrO}_{2}$ nanoparticles. Nanosystems: pysics, chemistry, mathematics, 2013, 4(6), P. 810.

[4] Oleinikov N.N., Pentin I.V., Murav'eva G.P., Ketsko V.A. Highly disperse metastable $\mathrm{ZrO}_{2}$-based phases. Russian Journal of Inorganic Chemistry, 2001, 46(9), P. 1275.

[5] Pozhidaeva O.V., Korytkova E.N., Romanov D.P., Gusarov V.V. Formation of $\mathrm{ZrO}_{2}$ nanocrystals in hydrothermal media of various chemical compositions. Russian Journal of General Chemistry, 2002, 72(6), P. 849.

[6] Kolen'ko Yu.V., Maksimov V.D., Garshev A.V., Mukhanov V.A., Oleynikov N.N., Churagulov B.R. Physicochemical properties of nanocrystalline zirconia hydrothermally synthesized from zirconyl chloride and zirconyl nitrate aqueous Solutions. Russian Journal of Inorganic Chemistry, 2004, 49(8), P. 1133.

[7] Li F., Li Y., Song Z., Ma F., Xu K., Cui H. Evolution of the crystalline structure of zirconia nanoparticles during their hydrothermal synthesis and calcination: Insights into the incorporationsof hydroxyls into the lattice. J. Eur. Ceram. Soc., 2015, 35(8), P. 2361.

[8] Dwivedi R., Maurya A., Verma A., Prasad R., Bartwal K.S. Microwave assisted sol-gel synthesis of tetragonal zirconia nanoparticles. Journal of Alloys and Compounds, 2011, 509, P. 6848.

[9] Almjasheva O.V., Fedorov B.A., Smirnov A.V., Gusarov V.V. Size, morphology and structure of the particles of zirconia nanopowder obtained under hydrothermal conditions. Nanosystems: physics, chemistry, mathematics, 2010, 1(1), P. 26-37.

[10] D. Isfahani T., Javadpour J., Khavandi A., Dinnebier R., Reza Rezaie H., Goodarzi M. Mechanochemical synthesis of zirconia nanoparticles: Formation mechanism and phase transformation. Int. Journal of Refractory Metals and Hard Materials, 2012, 31, P. 21.

[11] Davis B.H. Effect of $\mathrm{pH}$ on crystal phase of $\mathrm{ZrO}_{2}$ precipitated from solution and calcined at $600^{\circ} \mathrm{C}$. Commun. Am. Ceram. Soc., 1984, 67(8), P. 168.

[12] dos Santos V., da Silveira N.P., Bergmannc C.P. In-situ evaluation of particle size distribution of $\mathrm{ZrO}_{2^{-}}$ nanoparticles obtained by sol-gel. Powder Technology, 2014, 267, P. 392.

[13] Mommer N., Lee T., Gardner J.A. Stability of monoclinic and tetragonal zirconia at low oxygen partial pressure. J. Mater. Res., 2000, 15(2), P. 377.

[14] Sharikov F. Yu., Almjasheva O. V., Gusarov V. V. Thermal Analysis of Formation of $\mathrm{ZrO}_{2}$ nanoparticles under hydrothermal conditions. Russian Journal of Inorganic Chemistry, 2006, 51(10), P. 1538.

[15] Sharikov F.Yu., Meskin P.E., Ivanov V.K., Churagulov B.R., Tret'yakov Yu.D. Hydrothermal synthesis of nanosized zirconia as probed by heat-flow calorimetry. Doklady Chemistry, 2005, 403(2), P. 152.

[16] Al'myasheva O.V., Ugolkov V.L., Gusarov V.V. Thermochemical analysis of desorption and adsorption of water on the surface of zirconium dioxide nanoparticles. Russian Journal of Applied Chemistry, 2008, 81(4), P. 609. 
[17] Karakchiev L.G., Avvakumov E.G., Vinokurova O.B., Gusev A.A., Lyakhov N.Z. Formation of nanodispersed zirconia during sol-gel and mechanochemical processes. Russian Journal of Inorganic Chemistr, 2003, 48(10), P. 1447.

[18] Pechenyuk S.I., Mikhailova N.L., Kuz'mich L.F. Physicochemical investigation of titanium(IV) and zirconium(IV) oxohydroxide xerogels. Russian Journal of Inorganic Chemistry. 2003, 48(9), P. 1420.

[19] Osend M.I.i,. Moya J.S., Serna C.J., J. Soria Metastble of tetragonal zirconya powders. J. Am. Ceram. Soc., 1985, 68, P. 145.

[20] Mondal A., Ram S. Reconstructive phase formation of $\mathrm{ZrO}_{2}$ nanoparticles a new orthorhombic crystal structure from an energized porous $\mathrm{ZrO}(\mathrm{OH})_{2} \mathrm{xH}_{2} \mathrm{O}$ precursor. Ceramics International. 2004, 30, P. 239.

[21] Inoue M., Sato K., Nakamura T., Inui T. Glycothermal synthesis of zirconia-rare earth oxide solid solutions. Catalysis Letters, 2000, 65, P. 79.

[22] Lecloux A.J. Synthesis and characterization of monodisperse spherical zirconia particles. Journal of Sol-Gel Science and Technology, 1997, 8, P. 207.

[23] Strekalovsky V.N., Polezhaev Y.M., Palguev S.F. Oxides with impurity disordering: composition, structure, phase transformations. M .: Nauka. 1987. 160 p.(In Russian).

[24] Srdi'c V.V., Winterer M. Comparison of nanosized zirconia synthesized by gas and liquid phase methods. J. Eur. Ceram. Soc, 2006, 26(15), P. 3145.

[25] Guo X. Hydrothermal degradation mechanism of tetragonal zirconia. J. of Mater. Sci., 2001, 36(15), P. 3737.

[26] Murase Y., Kato E. Role of water vapor in crystallite growth and tetragonal-monoclinic phase transformation of $\mathrm{ZrO}_{2}$. J. Am. Ceram. Soc., 1983, 66, P. 196.

[27] Yoshimura M. Phase Stability of Zirconia. Am. Ceram. Soc. Bull., 1998, 67, P. 1950.

[28] Pozhidaeva O.V., Korytkova E.N., Drozdova I.A., Gusarov V.V. Phase State and Particle Size of Ultradispersed Zirconium Dioxide as Influenced by Conditions of Hydrothermal Synthesis. Russian Journal of General Chemistr, 1999, 69(8), P. 1265.

[29] Kollong R. Nonstoichiometry. M.: Mir. 1974. P. 288 (In Russian)

[30] Becker J., Bremholm M., Tyrsted C., Pauw B., K. Marie $\varnothing$. Jensen, Eltzholt J., Christensen M., Iversen B.B. Experimental setup for in situ X-ray SAXS/WAXS/ PDF studies of the formation and growth of nanoparticles in near- and supercritical fluids. J. Appl. Cryst., 2010, 43, P. 729.

[31] Krzhizhanovskaya M.G., Filatov S.K., Almjasheva O.V., Bubnova R.S., Meyer D.C., Paufler P., Gusarov V.V. The XRD study of $\mathrm{ZrO}_{2}$ nanopowders. Book of abstracts. "Nanoparticles, nanostructures and nanocomposites". Topical meeting of the European Ceramic Soc. 5-7 July 2004. St. Peterburg, 2004, P. 31. 